\title{
PIBID LETRAS - PORTUGUÊS E O TRABALHO COM FILME NA ESCOLA BÁSICA
}

\author{
Andriele Bairros Gonçalves ${ }^{1}$ \\ Renata Nicolletti ${ }^{2}$ \\ Vaima Regina Alves Motta ${ }^{3}$
}

Apresentação

O presente relato de experiência é um recorte da proposta desenvolvida pelo subgrupo PIBID Letras Português da Universidade Federal de Santa Maria (UFSM) na Escola Cícero Barreto que, ao longo do segundo semestre de 2016, realizou suas oficinas acerca da proposta: filme na escola básica.

A fim de buscar diferentes formas de abordagem do filme e aperfeiçoá-lo como recurso didático em sala de aula, para que não se torne apenas um pretexto para outras atividades, as oficinas contaram com atividades antes, durante e após a exibição do filme e também contemplaram a produção textual à luz dos gêneros autobiografia e memórias.

O recorte apresentado será referente a uma atividade de exploração do filme, a técnica dos intervalos, atividade durante o filme e às produções textuais, que foram as atividades pós-filme. Além disso, a proposta do projeto do PIBID Letras - Português é fundamentada na metodologia da pesquisaação.

\section{Caracterização da escola}

Em 2016, o projeto do PIBID - Letras Português - foi desenvolvido na escola de ensino básico Cícero Barreto da rede pública estadual, localizada na cidade de Santa Maria, Rio Grande do Sul. A escola atende a 809 alunos distribuídos entre Ensino Fundamental, Ensino Médio e EJA, totalizando, aproximadamente, 37 turmas distribuídas nos turnos matutino, vespertino e noturno. A escola apresenta uma boa infraestrutura, oferecendo aos professores e aos alunos um ambiente muito agradável para o aprendizado escolar.

\footnotetext{
${ }^{1}$ Graduada no Curso de Licenciatura em Letras Português e Literatura pela Universidade Federal de Santa Maria. E-mail: andrielegoncalves15@hotmail.com

${ }^{2}$ Graduanda no Curso de Licenciatura em Letras Português e Literatura pela Universidade Federal de Santa Maria. E-mail: renatamoonletti@yahoo.com.br

${ }^{3}$ Profa Dra do Departamento de Metodologia do Ensino da Universidade Federal de Santa Maria. E-mail: vaimamotta@gmail.com
} 
Os professores que atuam na escola são graduados em curso de licenciatura, o desenvolvimento de suas atribuições é com muita responsabilidade e alguns professores, ainda, desenvolvem atividades extraclasses como o projeto da "Rádio Escola", que conta com a participação dos estudantes. Essas atividades têm como finalidade contribuir para o aprendizado do aluno e para a comunidade escolar em geral.

A turma na qual foram realizadas as atividades do PIBID foi a 105 do primeiro ano do ensino médio, noturno. Na turma, havia 52 alunos matriculados, contudo, assíduos eram apenas 25, com idades entre 15 e 19 anos. Alguns desses alunos que estudavam à noite, durante o dia, trabalhavam. A maioria deles morava próximo à escola e possuíam um perfil socioeconômico pouco favorecido. Alguns apresentavam certa dificuldade no rendimento escolar, refletidas na frequência escolar e nas notas.

A turma, em geral, é muito inquieta e, algumas vezes, antes de iniciar as atividades ou até mesmo durante sua dinamização, era preciso intervir para que os alunos prestassem a atenção no que estava sendo realizado e contribuíssem para a troca de conhecimentos. No início das atividades, apenas alguns alunos participavam, contudo, ao longo do projeto já foi possível perceber grande parte da turma interagindo e contribuindo nas atividades e isto é algo positivo que merece ser destacado.

\section{Fundamentação teórica}

Pesquisa-ação

O trabalho sustentado pela pesquisa-ação qualifica o processo de ensino aprendizagem proposto em sala de aula, pois, quando se pensa pesquisa em educação pelo viés da pesquisa-ação, garante-se que o ambiente escolar não será um mero observatório para posterior análise de dados, mas um ambiente concreto para reflexão e vivências comprometidas com dada realidade.

A pesquisa-ação apresenta-se como um instrumento de trabalho, que a partir da investigação do contexto realizado em grupos propõe-se um trabalho voltado para o que foi observado, dessa forma, o trabalho a ser desenvolvido não fica distante da realidade da turma. Conforme, Thiollent (1996), um dos objetivos dessa modalidade de pesquisa é construir com os sujeitos envolvidos subsídios para a transformação de sua realidade, pois amplia a compreensão sobre características, potencialidades ou necessidades existentes no meio. Como favorece maior clareza sobre peculiaridades envolvendo processo e resultados, permite que o investimento em avanços tenha maior probabilidade de sucesso. De acordo com o autor:

é um tipo de pesquisa social com base empírica que é concebida e realizada em estreita associação com uma ação ou com a resolução de um problema coletivo e no 
qual os pesquisadores e os participantes representativos da situação ou do problema estão envolvidos de modo cooperativo ou participativo. (THIOLLENT, 1996, p.14)

Na mesma perspectiva, Barbier (2002) afirma que a "pesquisa-ação" é uma atividade de compreensão e de explicação da práxis dos grupos sociais por eles mesmos, com ou sem especialistas em ciências humanas e sociais práticas, com o fito de melhorar sua práxis, ou seja, é uma pesquisa de ação transformadora.

Dessa forma, a pesquisa-ação é um método de ensino, que, utilizada a partir da investigação (pesquisa em ação), propõe um trabalho veiculado ao contexto em que a turma observada se insere e, além disso, é possível refletir sobre a proposta de ensino, buscando qualificar não só a prática docente como também a resolução da problemática identificada.

Filme na sala de aula

O trabalho com o filme em sala de aula torna o aprendizado do aluno muito enriquecedor, uma vez que a partir dele pode-se investir tanto na linguagem midiática quanto na produção escrita.

Segundo Osorio (2011), "a educação pode abordar o cinema como instrumento, como objeto de conhecimento, como meio de comunicação e como meio de expressão de pensamentos e sentimentos" (p.112).

Considerando que o cinema acaba exercendo forte interferência nas diferentes gerações (FRESQUET, 2013), cabe também à escola qualificar a leitura do aluno sobre esse texto midiático, a partir de discussões e produções reflexivas. Vê-se assim uma maneira de aproximar interesse do aluno e compromisso da área da linguagem com a formação de um sujeito produtor de texto.

\section{Técnica dos Intervalos}

O trabalho com filme na sala de aula possibilitou desenvolver a "técnica dos intervalos". Esta técnica é uma metodologia adaptada da obra "Letramento Literário: teoria e prática" de Rildo Cosson (2014), em que o autor trabalha o ensino da leitura literária por meio de intervalos. Segundo ele, os intervalos "são momentos de enriquecimento da leitura do texto principal" (p.81).

Os intervalos, conforme propõe Cosson (2014), auxiliam os estudantes na compreensão da leitura e podem ser realizados de diversas maneiras como, por exemplo, leitura de outros textos, vídeos e canções, enfim, materiais complementares que dialogam com a obra em questão, por meio de diferentes enfoques. Podem ser realizados quantos intervalos o professor julgar necessário no momento da leitura. 
A "técnica de intervalos" realizada na atividade do filme aconteceu através de perguntas localizadoras, em cenas estratégicas, que auxiliaram os alunos na reflexão sobre o filme.

\section{Produção Textual (gêneros, escrita-reescrita)}

A produção textual é um exercício inerente ao ensino-aprendizagem de língua. Conforme aponta Silva (2011), o trabalho com a produção textual pressupõe o desenvolvimento de habilidades no aluno, que the permitam usar os recursos da língua para produzir sentidos em diferentes situações comunicativas.

Para Soares (2009), a escrita de um texto pressupõe pelo menos três momentos: pré-escrita, escrita e pós-escrita, contextualizada na teoria de gêneros, seguindo propósitos de escrita. Partindo dessa concepção, o texto deixa de ser visto como um mero produto, ou seja, como uma simples atividade de língua portuguesa em que o aluno escreve um texto e a ele é atribuída uma nota, e passa a ser visto como processo, uma vez que o aluno ao escrever um texto receberá feedbacks acerca da sua escrita. O feedback, segundo Soares (2009), é realizado através dos bilhetes orientadores, em que a função básica é elogiar o que foi realizado adequadamente pelo aluno no texto e, se necessário, aperfeiçoar o que não foi feito, fornecendo instruções e sugestões do que e como fazer. Esse processo de escrita e reescrita além de qualificar o texto ajuda o aluno a desenvolver percepções e habilidades em sua escrita.

Além disso, o trabalho de produção escrita deve estar contextualizado em uma situação de interação, como prevê a teoria de gêneros. Para fundamentar tal teoria, cita-se Marcuschi (2002) (apud Köche e Marinello, 2015, p.10) que define os gêneros como "textos materializados que encontramos em nossa vida diária e que apresentam características sociocomunicativas definidas por conteúdos, propriedades funcionais, estilos e composição características". Dessa forma, destacam-se dois gêneros textuais que foram trabalhados na proposta do projeto do PIBID: autobiografia e memórias:

Conforme Costa (2014), a autobiografia é a:

narração sobre a vida de um indivíduo, escrita pelo próprio, sob forma documental, ou seja, é uma prosa que uma pessoa real faz de sua própria existência, acentuando a vida individual, em particular, sobre a história de sua personalidade (p.45).

O gênero textual memória é um texto narrativo que resgata o passado, memórias. Para Costa (2014), o gênero memória "se caracteriza por ter um estilo referencial em que o passado se presentifica em objetos, coisas, lembranças" (p. 168). 
A proposta de ensino realizada nas oficinas do PIBID de Letras Português teve como base a metodologia da pesquisa-ação. Seguindo os preceitos dessa metodologia, foi realizada, inicialmente, a investigação do contexto na turma para, a partir disso, propor as ações que serão dinamizadas nas oficinas, as quais ocorreram semanalmente na escola.

Após a investigação realizada pelas BID’s (bolsistas de iniciação à docência), constatou-se na turma pouco relacionamento entre os alunos e carência na produção escrita. Dessa forma, o grupo optou por trabalhar com o filme "Escritores da Liberdade", a fim de investir na reflexão da temática do filme e na produção escrita.

O projeto foi estruturado da seguinte maneira: primeiramente, foi realizada a investigação do contexto, conforme já foi mencionado anteriormente. Após, foi desenvolvida uma atividade de provocação com os alunos, que denominamos "pise na linha".

Esta atividade é semelhante ao que acontece no filme, uma que vez que foi traçado no chão uma linha em que separavam os alunos, formando na turma dois grupos. Dessa forma, realizaram-se comandos aos alunos, nas quais aproximavam e também os distanciavam. Para ilustrar tal prática, segue o quadro abaixo:

\begin{tabular}{|c|c|}
\hline Comando: Pise na linha: & $\begin{array}{l}\text { 7- quem já sentiu que fez a diferença na vida } \\
\text { de alguém. }\end{array}$ \\
\hline 1- quem gosta de estudar à noite. & $\begin{array}{l}\text { 8- quem já deixou de fazer algo em função da } \\
\text { opinião dos outros. }\end{array}$ \\
\hline 2- quem trabalha. & 9- quem gosta de assistir a filmes. \\
\hline $\begin{array}{l}\text { 3- quem auxilia no sustento da casa. } \\
\text { 4- quem tem filhos. }\end{array}$ & $\begin{array}{l}\text { 10- quem já realizou trabalhos com filme na } \\
\text { escola. }\end{array}$ \\
\hline $\begin{array}{l}\text { 5- quem já sofreu algum tipo de } \\
\text { discriminação. }\end{array}$ & $\begin{array}{l}\text { 11- quem gosta de ler. } \\
\text { 12- quem gosta de escrever. }\end{array}$ \\
\hline 6- quem já perdeu alguém importante. & \\
\hline
\end{tabular}

Quadro 1 - Comandos realizados na dinâmica da linha (atividade de provocação).

A finalidade dessa atividade, inicialmente, tinha o objetivo de conhecer os alunos e segundo prepará-los para o filme "Escritores da liberdade" e para as atividades que seriam dinamizadas mais adiante. Além disso, proporcionar uma reflexão entre eles, referente à aproximação ou não do colega diante da minha reação à pergunta, pois como foi mencionada anteriormente, a turma apresentava uma indiferença de relacionamento. Assim, esta atividade proporcionou aos alunos um contato diferenciado entre eles. Em seguida, foi realizada a atividade de preparação para o filme como uma 
pequena localização histórica da história do filme e ao término dessa atividade, houve a exibição do filme, em que foram realizados alguns intervalos para comentários e reflexão sobre algumas cenas importantes do filme.

Esta atividade denominada "intervalos" é baseada na técnica desenvolvida por Cosson (2014) para o ensino de leitura, na disciplina de literatura, e aconteceu de seguinte maneira: foram selecionadas previamente pelas BID'S algumas cenas do filme e ao longo da exibição eram realizadas pausas nestas cenas, nas quais se desenvolviam questionamentos, comentários, a fim de proporcionar não só a reflexão sobre tais cenas, mas também acompanhar e monitorar a compreensão dos alunos acerca do filme. $O$ quadro abaixo apresenta as perguntas realizadas na atividade.

\begin{tabular}{|l|l|}
\hline Intervalo para comentários: & d) Qual é a perspectiva de vida dos alunos \\
1o intervalo- & diante do "conflito" que eles enfrentam? \\
a)Qual foi a impressão inicial da turma em & e) Como vocês interpretam o "jogo da linha" \\
relação a professora e vice-versa? & no filme? Qual foi o objetivo da professora? \\
b)Como você interpreta a cena de troca de & \\
lugares? Você julga válida a atitude da & 3o intervalo- \\
professora? Por quê? & a) Como a ida dos alunos ao museu interferiu \\
2o intervalo- & na vida deles? \\
a)Como é a mudança de comportamento dos & b) Como que é a presença dos pais nas reunião \\
alunos e da professora, após o desenho da & na escola? \\
caricatura? & c) Como vocês interpretam a atitude da \\
b) Vocês conhecem ou sabem alguma coisa & professora em querer ajudar os alunos? \\
sobre o holocausto? & \\
c) O que a professora faz para mudar a vida & \\
dos alunos? &
\end{tabular}

Quadro 2 - perguntas da técnica dos intervalos

Após, foi realizada a atividade de exploração do filme, em que os alunos reuniram-se em grupos e exploraram cenas do filme, selecionadas previamente, sobre as quais se realizou discussões. As discussões foram acerca da relação e da importância que as cenas selecionadas tinham no filme, com o intuito de provocar uma reflexão global sobre o filme e estabelecer links para além do filme. 


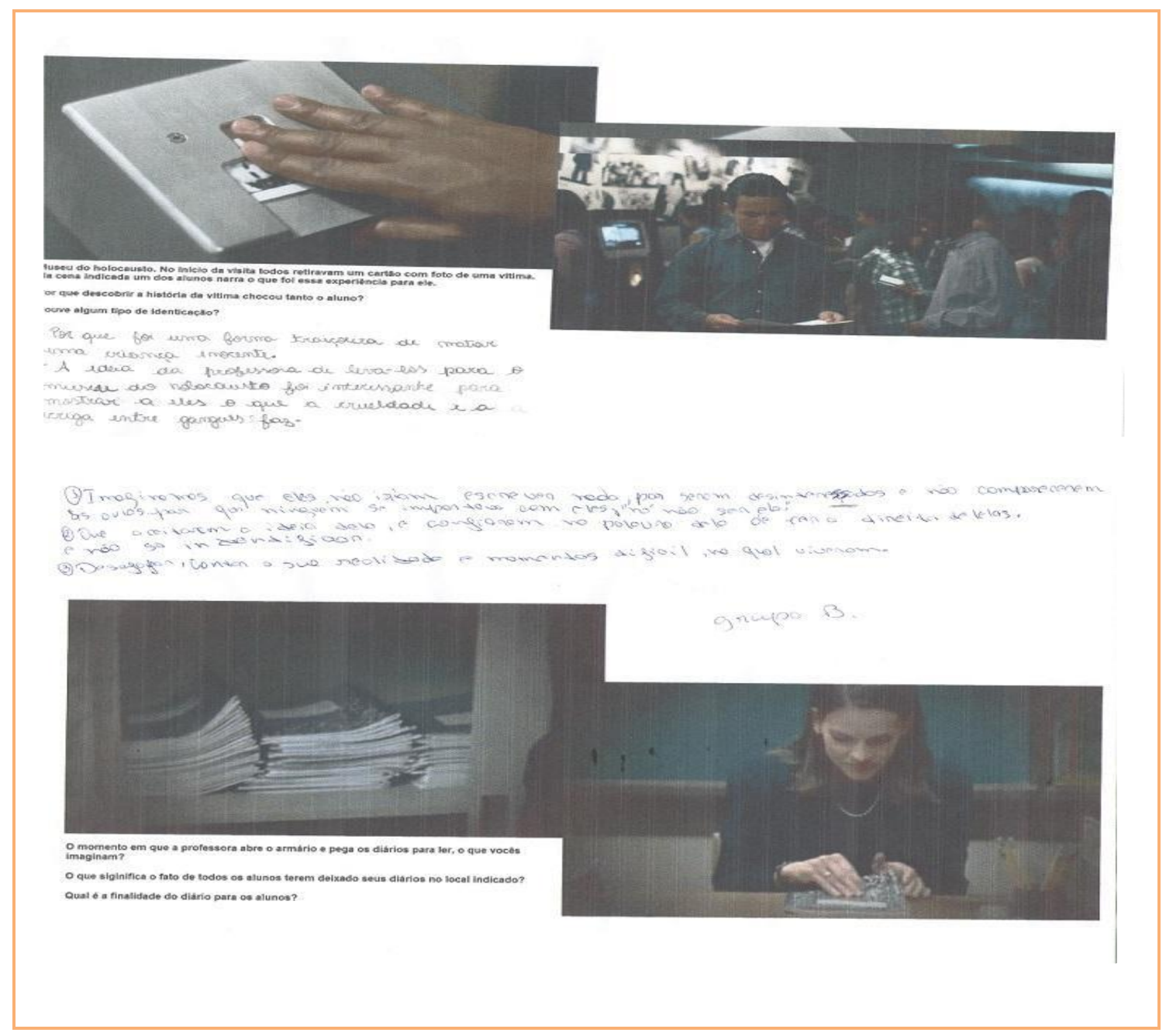

Quadro 3-Atividade de exploração de cenas

Na sequência das oficinas, realizaram-se as atividades pós-filme, nas quais se explorou a produção textual. Nestas atividades, os alunos produziram a autobiografia e relatos de momentos marcantes de sua infância, adolescência e vida escolar, gêneros estes escolhidos a partir de um enquadramento proposto com o filme.

A autobiografia foi introduzida a partir da sistematização do gênero e leitura de textos exemplares ${ }^{4}$. Já para os relatos, foi realizada uma dinâmica denominada "dinâmica do espelho", em que o aluno deveria falar algo de bom ou ruim sobre a imagem que enxergava no espelho. Dessa dinâmica seguiu-se a produção escrita dos relatos. Abaixo seguem os comandos das produções escritas de ambos os gêneros.

\footnotetext{
4 “Texto autobiográfico de Monteiro Lobato". Disponível em: <https://pt.scribd.com/doc/52530174/Texto-autobiograficode-Monteiro-Lobato>. Acessado em 8 de julho de 2017.

"Autobiografia Poética". Disponível em <http://www.recantodasletras.com.br/biografias/2404657>.

Acessado em 8 de julho de 2017.

“Aí eu peguei e nasci!". Disponível em: <http://bethskill.blogspot.com.br/2010/02/biografia-jose-simao.html>. Acessado em 8 de julho de 2017.
} 
- Comando para eserita da autobiografia que irá compor os dírios

Agora é a sta vez!!!

Com base nas questôes que foram propostas anteriormente para discussão e nas caracteristicas do gênero já apresentadas, redija uma autobiografia, que integrará um diário a ser construido ao logo do desenvolvimento das atividades. Utilize a terceira pecsoa do singular e procure explicitar informaçōes importantes e curiosas sobre vocé.

Bom trabalho:

\begin{tabular}{|c|c|c|}
\hline & $\begin{array}{c}\text { UNIVESIDADE FEDERAL DE SANTA MARIA } \\
\text { PIBID 2016 }\end{array}$ \\
3 & SUBPROJETO LETRAS PORTUGUES
\end{tabular}

PROPOSTA DE PRODUÇĀO TEXTUAL.

Sempre há momentos na vida que nos marcam, sendo estes bons ou nem tanto. A partir da dintämica do espelho, em que vocé póde falar algo sobre vocé $\mathrm{e}$, de certa forma, recordar algumas atitudes e momentos, escreva um texto (memórias) relatando algum momento marcante da sua infäncia, da sua adolescênecia e da sua rotina na escola. Boa escrita?

Quadro 4-Comandos dos gêneros autobiografia e relato.

Vale ressaltar que todas as produções escritas contaram com feedbacks, em que foi possível trabalhar o texto como processo, sendo produzidas pelo menos duas versões de cada texto. Além da escrita, também houve seleção de trilha sonora e fotos dos alunos e tudo isto culminou na confecção de um diário que, ao final da última oficina, foi exposto e socializado. Ainda, aconteceu a atividade de reflexão gerenciada, que serviu como ponte entre o filme e o produto final (diários). Nesta atividade foi possível refletir com os alunos sobre todas as atividades desenvolvidas ao longo do projeto.

\section{Avaliação dos resultados}

A turma mostrou-se bem receptiva às atividades que foram proporcionadas ao longo das oficinas. Como já foi mencionado, as atividades foram encaminhadas a partir da observação do contexto em que a turma se encontrava.

O propósito de trabalhar o filme "Escritores da Liberdade" era com a finalidade de sanar a problemática de relacionamentos que havia entre os alunos e também investir na qualificação da escrita.

Ao final de toda dinamização do projeto foi possível verificar avanços tais como: a participação dos alunos, pois, inicialmente, apenas dois ou três alunos participavam das discussões e ao final foi 
possível perceber grande parte da turma participando e contribuindo nas atividades. Outro avanço notável foi no tocante ao relacionamento da turma, uma vez que já estavam melhor entrosados, respeitando-se. E no que tange ao ensino de Língua Portuguesa, foi possível verificar avanços na escrita dos alunos através do trabalho pautado na escrita-processo.

A partir dos bilhetes orientadores, os alunos se depararam com um momento de reflexão sobre a própria escrita e desenvolveram um trabalho de avaliação das orientações, selecionando o que achavam relevante ou não. Isso contribuiu para a qualificação dos textos quanto à quantidade de informações, adequação ao gênero, ortografia, entre outros aspectos, como a compreensão do emprego da primeira pessoa em textos de cunho pessoal, do tempo verbal pretérito e da concordância verbal na escrita de relatos, por se tratar de memórias. Quanto à técnica dos intervalos, que foi uma alternativa de exploração do filme, pudemos perceber que houve uma participação efetiva dos alunos e consequentemente tornou-se um momento de discussão, uma pausa no filme que se voltava para retomar o que já havia passado e relacionar com a cena atual e até prever a continuação do filme. No entanto, mais importante que isso, foram as intenções dos intervalos, realizados em momentos estratégicos do filme, a fim de provocar uma discussão previamente esperada, e que realmente ocorreu de forma interativa.

Dessa forma, avaliam-se os resultados como positivos, uma vez que os objetivos e a proposta lançada inicialmente foram alcançados, proporcionando não só aos alunos um aprendizado significativo como também aos professores e acadêmicos envolvidos nesta proposta de trabalho.

Contudo, cabe mencionar que houve dificuldades e imprevistos ao longo deste trabalho, que, certamente contribuíram para a reflexão sobre a docência e sobre a proposta em si. O trabalho com filme em sala de aula merece ainda investimentos, pois permite uma diversidade de abordagens e nosso trabalho foi apenas uma delas.

\section{Considerações finais}

O presente relato apresentou uma alternativa para se trabalhar com filme em sala de aula e explorar essa linguagem midiática, prevista nos PCNs de Língua Portuguesa. O trabalho com diferentes linguagens precisa ser mais explorado na escola, local onde, espera-se acessar e manusear aquilo que circula no mundo em que seus sujeitos vivem.

Entendemos também que é papel do PIBID, ao integrar-se à escola, contribuir para a promoção de momentos didático-pedagógicos produtivos e que venham a somar na trajetória escolar dos alunos envolvidos e na formação dos acadêmicos, futuros professores. 
Referências

BARBIER, R. A pesquisa-ação. Trad. Lucie Didio. Brasília: Liber Livro, 2002.

COSSON, R. Letramento literário: teoria e prática. 2ª ed. , 4a reimpressão. São Paulo: Contexto, 2014.

COSTA. S. R. Dicionário de gêneros textuais. 3ª ed., Belo Horizonte: Autêntica Editora, 2014.

FREQUEST, A. Cinema e Educação: reflexões e experiências com professores e estudantes de educação básica, dentro e "fora" da escola. Belo Horizonte: Autêntica Editora, 2013.

KÖCHE, V. S. Gêneros textuais: práticas de leitura escrita e análise linguística. Vanilda Salton Köche, Adiane Fogali Marinello. Petrópolis, RJ: Vozes, 2015.

OSORIO, E. M. R. Mikhail Bakthin e os gêneros do discurso na educação. São Carlos: Pedro \& João editores, 2011.

SOARES, D. A. Produção textual e revisão textual: um guia para professores de português e de línguas estrangeiras. Petrópolis, RJ: Vozes, 2009.

SILVA, R. do C. P. da. A linguística textual e a sala de aula. Curitiba: Ibpex, 2011.

THIOLLENT, M. Metodologia da pesquisa-ação. São Paulo: Cortez,Autores Associados, 1996. 